\title{
Adipose Derived Stem Cells and Growth Factors Applied on Hair Transplantation. Follow-Up of Clinical Outcome
}

\author{
Federica Zanzottera ${ }^{*}$, Emilio Lavezzari1, Letizia Trovato ${ }^{2}$, Alessandro Icardi², \\ Antonio Graziano² \\ ${ }^{1}$ Hair Transplantation Surgery, Studio Dr. Lavezzari, Como, Italy \\ ${ }^{2} \mathrm{HBW}$ Srl, Torino, Italy \\ Email: ${ }^{*}$ federica.zanzottera@hotmail.it
}

Received 10 June 2014; revised 12 July 2014; accepted 12 August 2014

Copyright (C) 2014 by authors and Scientific Research Publishing Inc.

This work is licensed under the Creative Commons Attribution International License (CC BY). http://creativecommons.org/licenses/by/4.0/

(c) (i) Open Access

\section{Abstract}

Different studies show the need of immature adipose cell to induce the proliferation of bulge stem cells in order to kick off the anagen phase of hair cycle. Furthermore, the adipose derived stem cell, adipose progenitors, and growth factors secreted by mature adipocytes can help the wound healing and the vascular neogenesis. Nowadays, it is not known any protocol of tissue regeneration applied to hair transplantation, especially if aimed to the reconstruction of the main vascular network for the engraftment of transplanted hair and the healing process. The aim of the work is to investigate how the application of autologous cellular suspension obtained by Rigenera system, mechanical fragmentation procedure which allows to obtain a physiological saline solution consisting of a heterogeneous pool of cells rich in adipose derived mesenchymalstem cells and growth factors, helps the wound healing and engraftment of the transplanted hair. During hair restoration surgery, the adipose tissue recovered from the discard of follicular slicing, was processed using the Rigenera system. The obtained cell suspension was applied in the area of hair transplantation, increasing the natural background of adipocyte lineage and raising the amount of growth factors. In addition, the cellular suspension was applied to the suture on the occipital region. The cell population was characterized by FACS. The monthly evaluation of hair transplantation follow-up with photos and the patient's impressions demonstrates that there is a faster healing of the micro-wound and a continuous growth of the transplanted hair even two months after the procedure, with a shortening of the dormant phase. In conclusion, this new approach aims to integrate regenerative medicine and hair restoration surgery in order to improve the outcome for the patient. It would be wonderful to continue this research to elaborate on the molecular cause behind this satisfying clinical.

\footnotetext{
${ }^{*}$ Corresponding author.
}

How to cite this paper: Zanzottera, F., Lavezzari, E., Trovato, L., Icardi, A. and Graziano, A. (2014) Adipose Derived Stem Cells and Growth Factors Applied on Hair Transplantation. Follow-Up of Clinical Outcome. Journal of Cosmetics, Dermatological Sciences and Applications, 4, 268-274. http://dx.doi.org/10.4236/jcdsa.2014.44036 


\section{Keywords}

Stem Cell, ADSC, Hair Transplantations, Regenerative Medicine, Hypoderm Hair Transplantations

\section{Background}

The field of hair transplantations has made countless step forward and now it is possible to obtain results not even imagine thirsty years ago.

In the last ten years, we have witnessed the rise of regenerative medicine applied at many surgical disciplines aiming to increase the results and reduce the pain of patients. Nowadays, except for Platelet Rich Plasma (PRP), it is not known any protocol of tissue regeneration applied to hair transplantation, especially if aimed to the reconstruction of the main vascular network for the engraftment of transplanted hair and the healing process.

A number of researches underline the existence of cells in the adult body capable of repairing and regenerating damaged tissues.

Adipose tissue is a multifunctional organ that contains various cellular types, such as mature adipocytes and the stromal vascular fractions (SVF), which consists of endothelial cells, pericytes, fibroblasts, pre-adipocytes and mesenchymal stem cells, called Adipose Derived Stem Cells (ADSC) (Figure 1). These pluripotent cells with their secretome mediate different skin regenerative effects, such as wound healing, antioxidant protection and antiwrinkling [1]. Autologous ADSC have been applied for several regenerative treatments such as widespread traumatic calvarial bone defects [2], breast augmentations [3], fistulas in patients with Crohn's disease [4] and for wound healing in treatment of chronic ulcers [2].

Festa [5] shows the need for immature adipocytes to promote the proliferation of bulge stem cells. Sumikawa [6] shows the potential of leptine and adipokine as an inducer of anagen phase. Furthermore, growth factors stimulate hair growth in both ex vivo and in vivo animal model [7] [8].

It is clear that the adipocyte lineage is critical to tissue regeneration and hair growth.

\section{Aim}

The aim of this work is to evaluate how a pool of cells consisting of ADSC, pericytes, endoteliocytes, preadipocytes and their secretome can improve the hair transplantation outcome, helping wound healing and follicular units' engraftment.

\section{Methods}

\subsection{Subjects}

Three patients, subjected to hair restoration surgery with the application of adipose derived stem cells and growth factors, were monitored after 5 days, 2 weeks and 1 month. The selection of the patients was casual and based on their availability.

\subsection{Cellular Suspension Obtainment}

During hair restoration surgery, a strip of scalp form the occipital region is cut and sliced to isolate the follicular units. Below the dermis there are hypodermis and adipose tissue that had been discarded in the past. These tissues were processed using Rigenera system.

Rigenera device is a safe standardized sample preparation system, for the automated mechanical disaggregation of cells population. This mechanical fragmentation, allows extracting from tissue only smallest cells that represents the progenitor cells responsible of the tissue formation. In addition, this system is able to cut, without crash, the single extracellular matrix constituents, which play an important role in reducing inflammatory process and so help the healing of tissue. Figure 2 states all steps to obtain a cell suspension.

\section{FACS}

FACS analysis was performed to evaluate the quantity and quality of cell suspension from two different patients. 


\section{Adipose tissue}

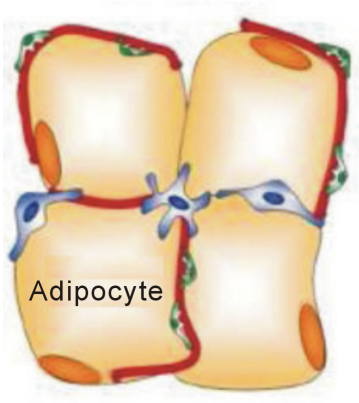

SVF cells

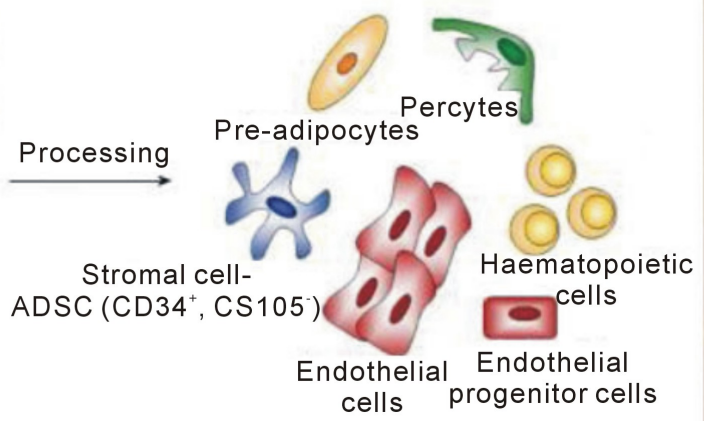

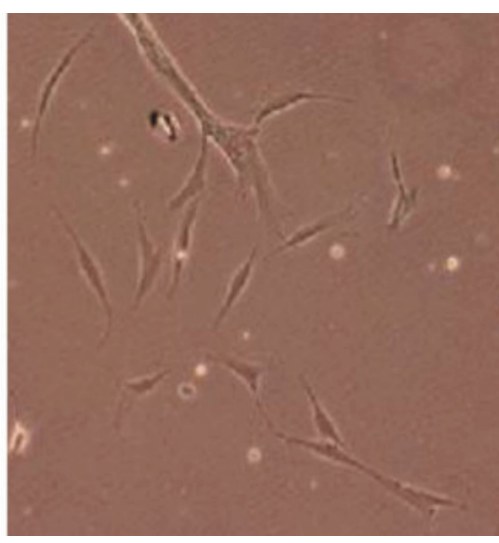

Figure 1. Adipose tissue and photo of ADCS by optical microscope.
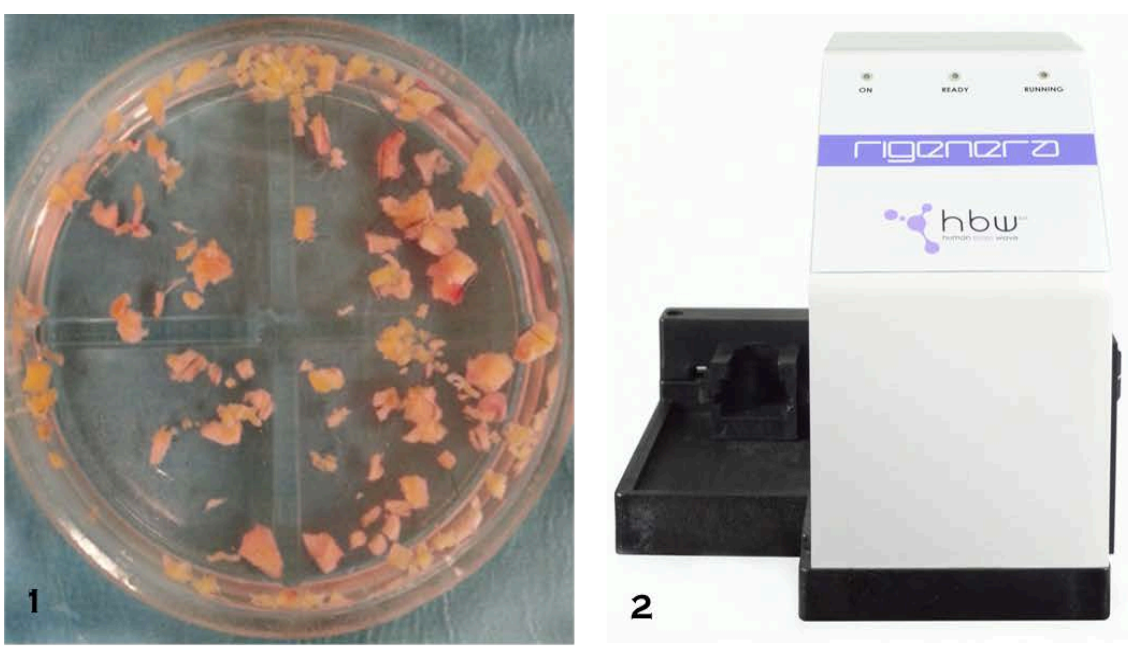
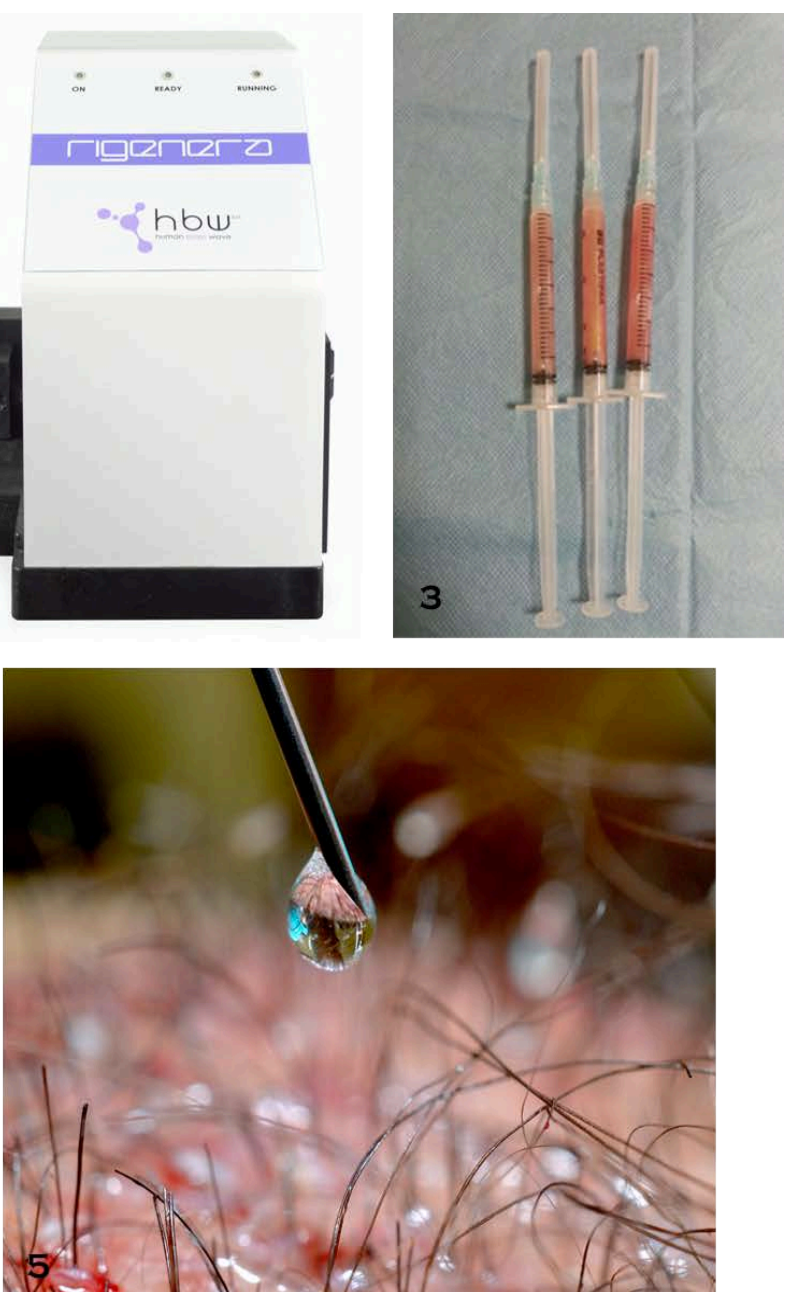

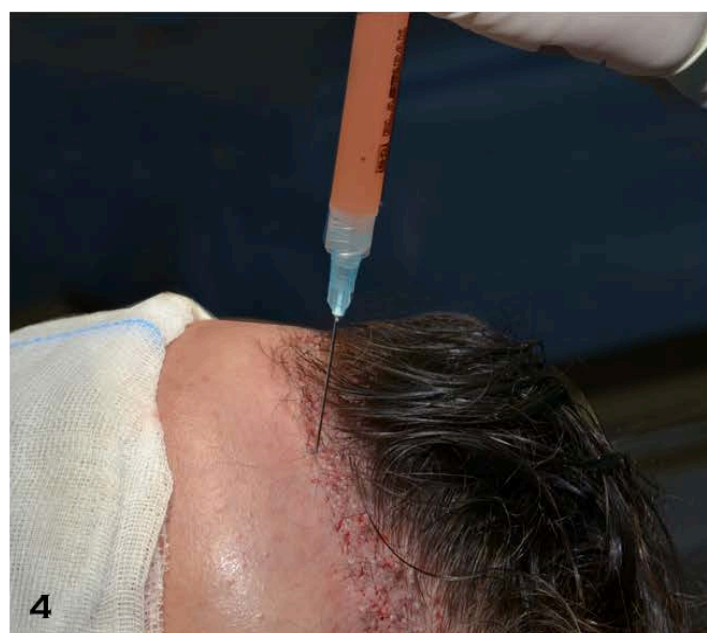

Figure 2. Rigenera System: 1) Hypo-derma and adipose tissue from the occipital region; 2) Rigenera system: a piece of tissue $+1 \mathrm{ml}$ of saline solution was inserted in Rigeneracons (CE/EC disposable medical devices containing a stainless steel grid with 100 hexagonal holes of $50 \mu$ each surrounded by six micro blades) and mechanically fragmented with Rigenera for $3 \mathrm{~min}$. The cells passed through the grid into the liquid suspension; 3) Cell suspension was collected with a syringe. The disaggregation and filtration results in a physiological saline solution consisting of heterogeneous pool of cells and growth factors; 4) Cell suspension was injected subcutaneously; and 5) Dropped on the micro incisions made for the engraftments of hair. The suspension was applied before and after the hair insertion. (For some patients the suspension was applied also on the donor area wound) 
The gating was made for CD146 and CD34, typical of adipose derived mesenchymal stem cells. The cells were also observed at optical microscope.

\section{Results}

\subsection{Cell Suspension Analysis}

The cellular vitality is $93 \%$ for the 1 st patients and $74 \%$ for the 2 nd. This represents a good result especially after mechanical fragmentation.

Both gating for CD146 and CD34 shows that the cellular suspension obtained by Rigenera is a heterogeneous pool of cells composed by erythrocytes, epithelial cells, ADSC and 90\% of living cells, which correspond to immature adipocytes and ADSC at the first differentiation stage (Figure 3).

The cells are in the active phase of the cell cycle; lots of them are doubling and splitting, showing that Rigenera sorting allows the collection of young and active cells, discarding the quiescent and old cells at the end of their functional utility (Figure 4).

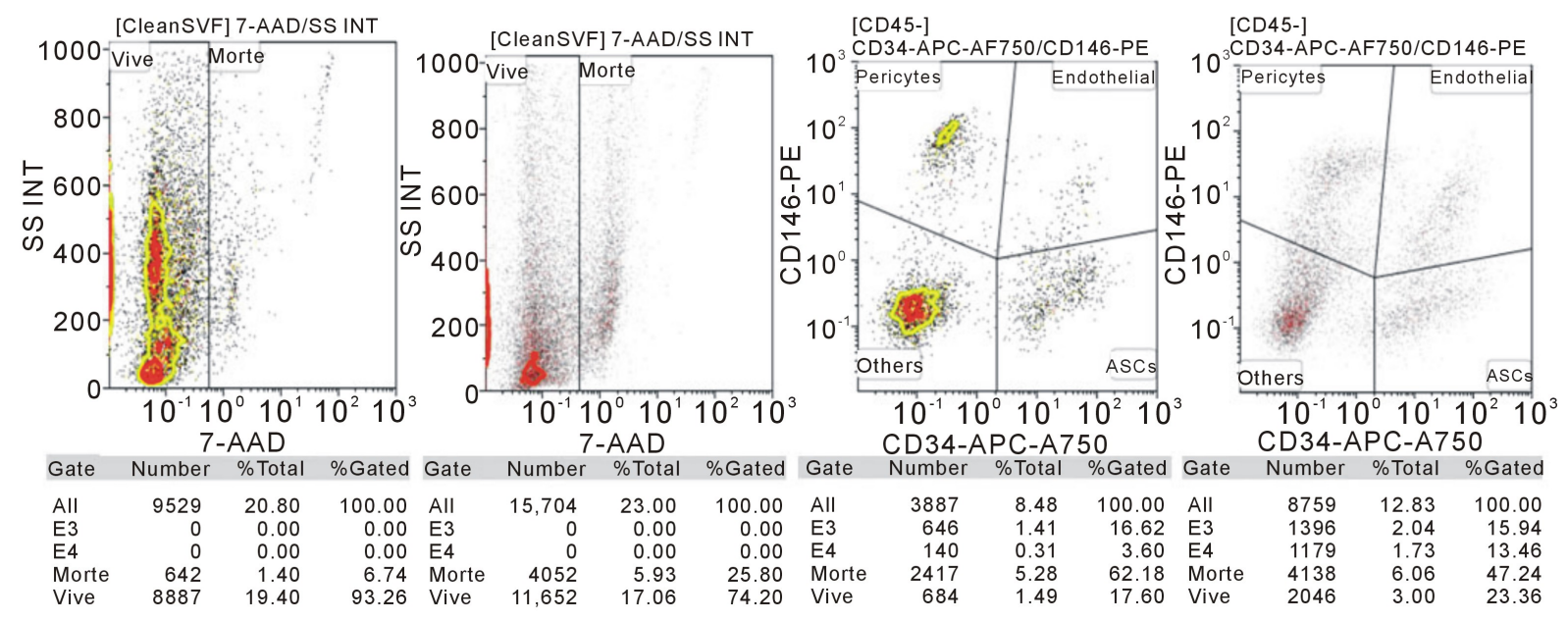

Figure 3. FACS made on a pool of cells obtained from the mechanical fragmentation of the hypodermic and adipose tissue from the occipital region of two patients. 1) Vitality of cells; 2) Gating for CD146 and CD34 in order to underline the presence of Adipose Derived mesenchymal Stem Cells (ADSC).
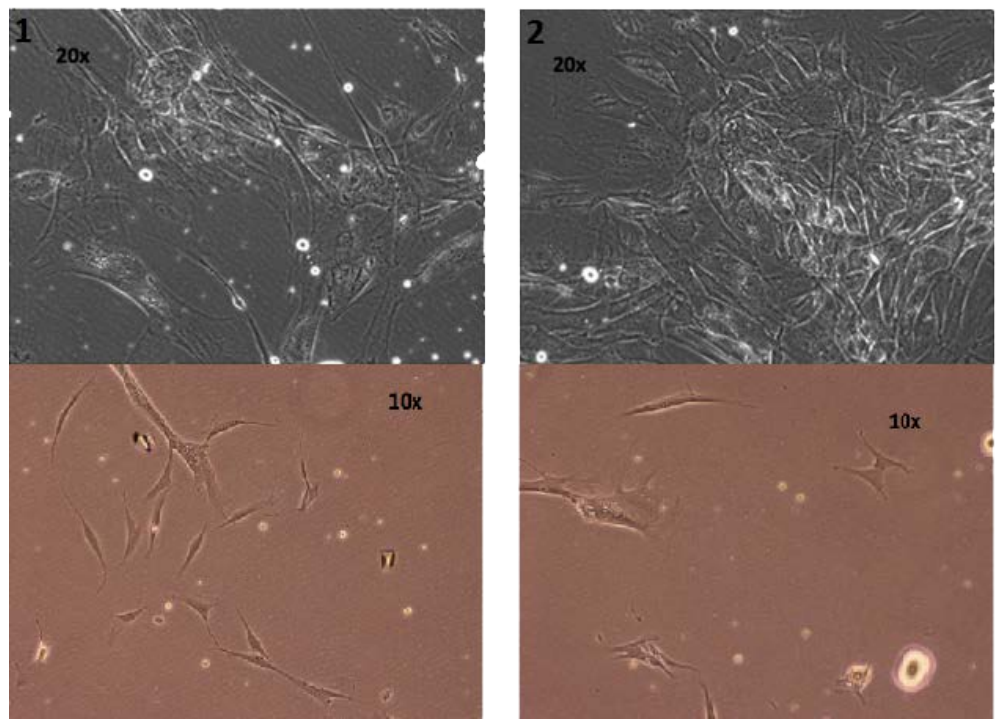

Figure 4. Photos of cellular suspension of the two patients by optical microscope. 


\subsection{Patient's Follow-Up}

Only two weeks after transplantation the healing of micro wounds was complete. Hair continued growing, greatly improving the patient's mood and self-confidence. Also the wound on the donor area was perfectly healed (Figure 5).

Five days after hair restoration surgery, the patient reported a perfect recovery, without any swelling and edema. The small scabs were clean and dry, ready to fall (Figure 6).

One month after surgery, a maintenance of transplanted hair and a perfect healing of micro wounds are visible (Figure 7).

\subsection{Patient's Impressions}

For all the patients the pain was very mild and for one of them was completely absent.

They also reported a reduction of post operatory edema and swelling. The perception of pain was established by VAS (Visual Analogic Scale) (Figure 8).

\section{Discussion}

Rigenera system gives the possibility to extract from tissue only the smallest cells that represent the progenitors responsible for the tissue formation. It allows to cut, without crash, the single extracellular matrix constituents, which are important in reducing the inflammatory process and so to help the healing of tissue. Furthermore, it crashes mature adipocytes freeing up many growth factors. In this way it is possible to maintain a sort of "cellularniche" in which every cell and growth factor plays its role in tissue regeneration.

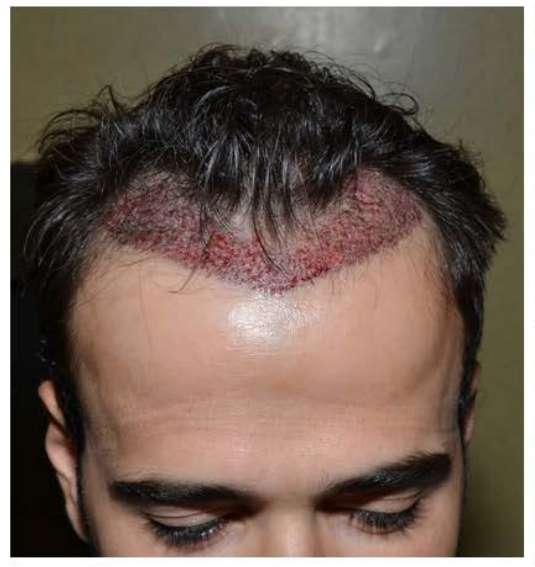

(a)

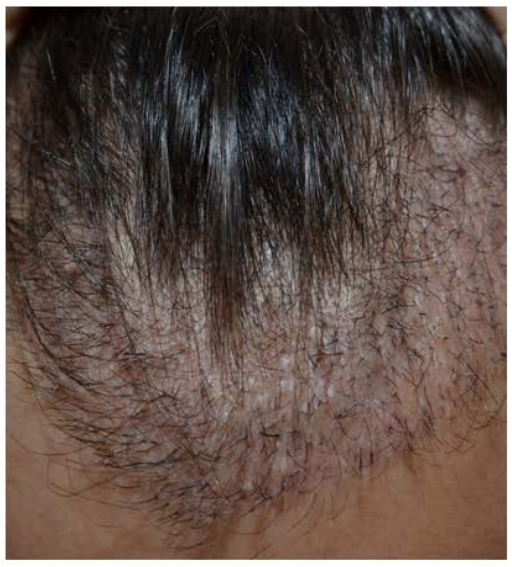

(b)

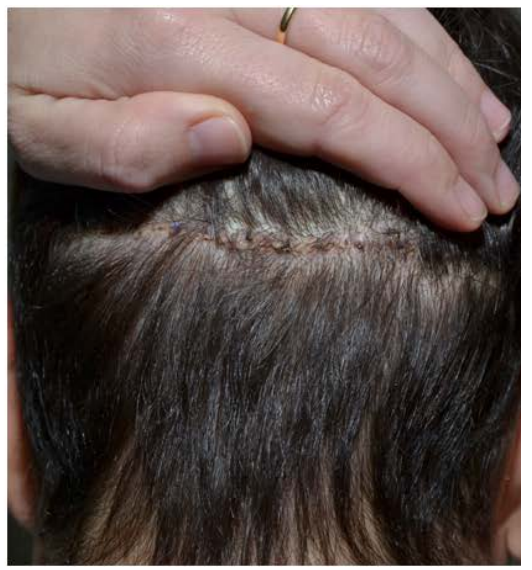

(c)

Figure 5. Patient 1. (a) Immediately after the hair restoration surgery; (b) and (c) two weeks after.

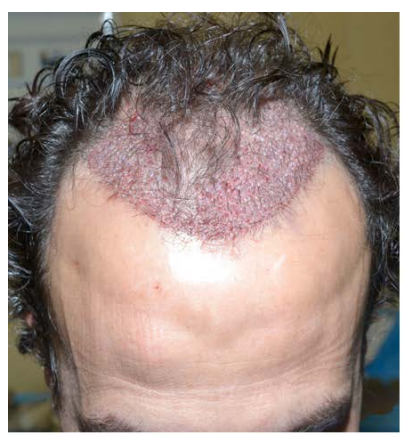

(a)

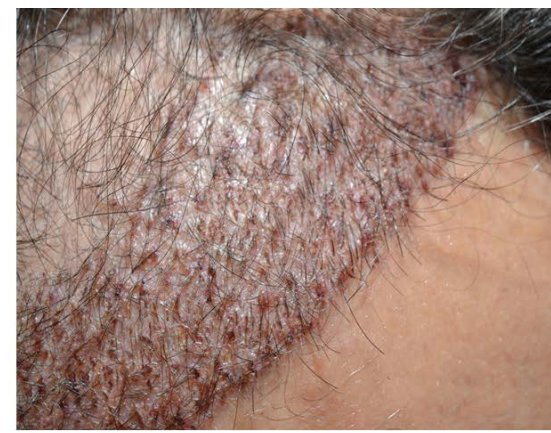

(b)

Figure 6. Patient 2. (a) Immediately after the hair restoration surgery; (b) Five days after. 


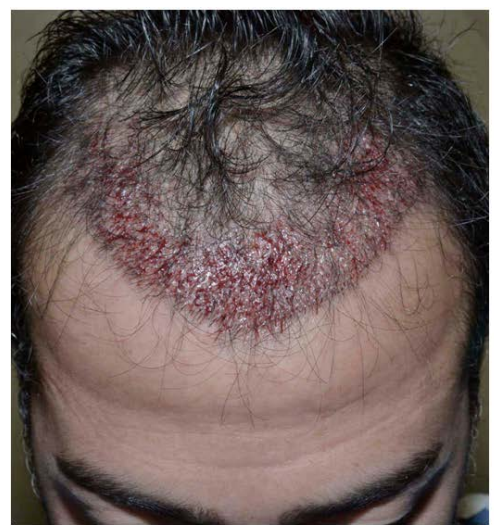

(a)

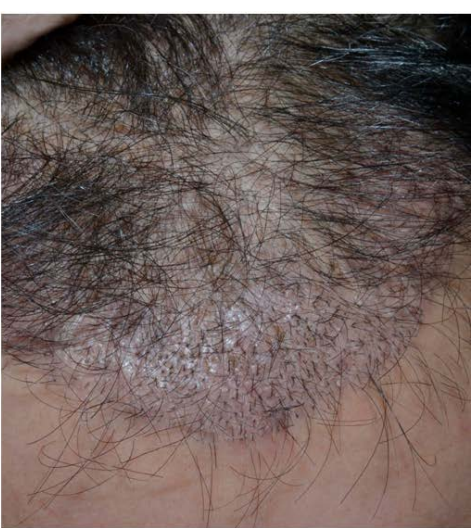

(b)

Figure 7. Patient 3. (a) Immediately after the hair restoration surgery; (b) one month after.

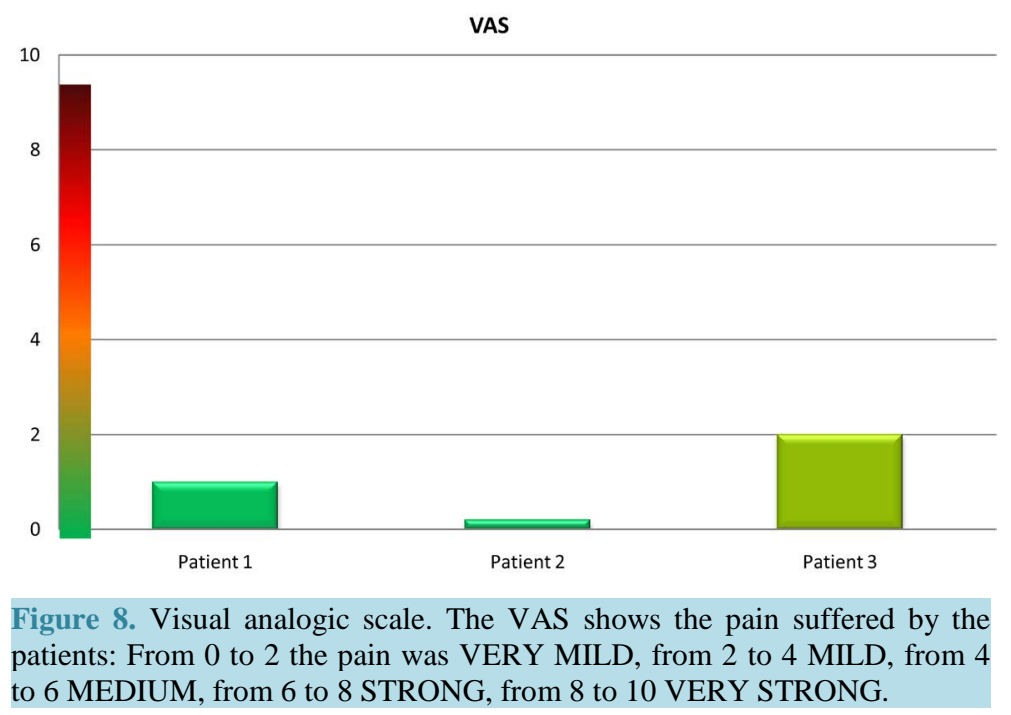

Applying these cells in the area of hair transplantation increases the natural background of adipocyte lineage, which is already present in the bulge and dermal papilla region. It raises the amount of growth factors easing the healing process and helping hair growth and engraftment of transplanted hair. It would be wonderful to continue this research to elaborate on the molecular cause behind these satisfying clinical results and to carry out a bigger and more complete clinical trial.

\section{References}

[1] Park, B.S., Kim, W.S., Choi, J.S., Kim, H.K., Won, J.H., Ohkubo, F. and Fukuoka, H. (2010) Hair Growth Stimulated by Conditioned Medium of Adipose-Derived Stem Cells Is Enhanced by Hypoxia: Evidence of Increased Growth Factor Secretion. Biomedical Research, 31, 27-34. http://dx.doi.org/10.2220/biomedres.31.27

[2] Lendeckel, S., Jödicke, A., Christophis, P., et al. (2004) Autologous Stem Cells (Adipose) and Fibrin Glue Used to Treat Widespread Traumaticcalvarial Defects: Case Report. Journal of Cranio-Maxillo-Facial Surgery, 32, 370-373. http://dx.doi.org/10.1016/i.jcms.2004.06.002

[3] Yoshimura, K., Sato, K., Aoi, N., et al. (2008) Cell-Assisted Lipotransfer for Cosmetic Breast Augmentation: Supportive Use of Adiposederivedstem/Stromal Cells. Aesthetic Plastic Surgery, 32, 48-55. http://dx.doi.org/10.1007/s00266-007-9019-4

[4] Rosen, E.D. (2002) The Molecular Control of Adipogenesis, with Special Reference to Lymphatic Pathology. Annals of the New York Academy of Sciences, 979, 143-158. http://dx.doi.org/10.1111/j.1749-6632.2002.tb04875.x 
[5] Festa, E., Fretz, J., Berry, R., Schmidt, B., Rodeheffer, M., Horowitz, M. and Horsley, V. (2011) Adipocyte Lineage Cells Contribute to the Skin Stemcell Niche to Drive Hair Cycling. Cell, 146, 761-771. http://dx.doi.org/10.1016/j.cell.2011.07.019

[6] Sumikawa, Y., Inui, S., Nakajima, T. and Itami, S. (2014) Hair Cycle Control by Leptin as a New Anagen Inducer. Experimental Dermatology, 23, 27-32. http://dx.doi.org/10.1111/exd.12286

[7] Yano, K., Brown, L.F. and Detmar, M. (2001) Control of Hair Growth and Follicle Size by VEGF-Mediated Angiogenesis. Journal of Clinical Investigation, 107, 409-417. http://dx.doi.org/10.1172/JCI11317

[8] Tomita, Y., Akiyama, M. and Shimizu, H. (2006) PDGF Induce and Maintain Anagen Phase of Murine Hair Follicles. Journal of Dermatological Science, 125, 873-882. 
Scientific Research Publishing (SCIRP) is one of the largest Open Access journal publishers. It is currently publishing more than 200 open access, online, peer-reviewed journals covering a wide range of academic disciplines. SCIRP serves the worldwide academic communities and contributes to the progress and application of science with its publication.

Other selected journals from SCIRP are listed as below. Submit your manuscript to us via either submit@scirp.org or Online Submission Portal.
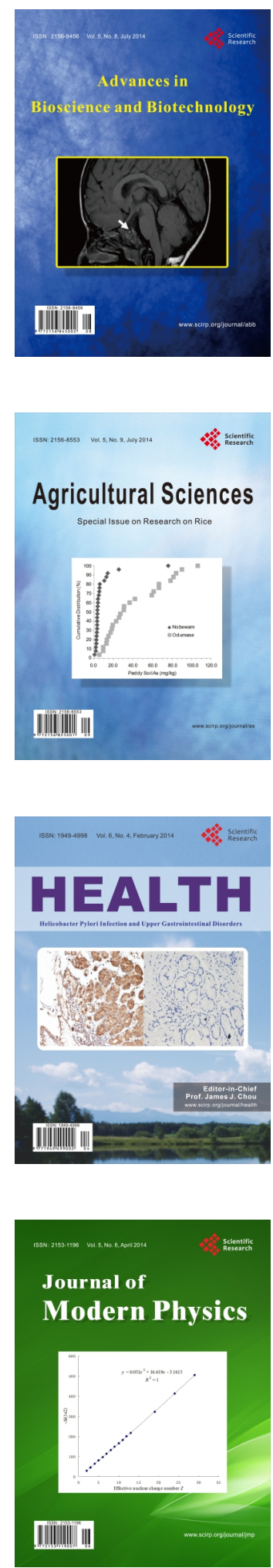
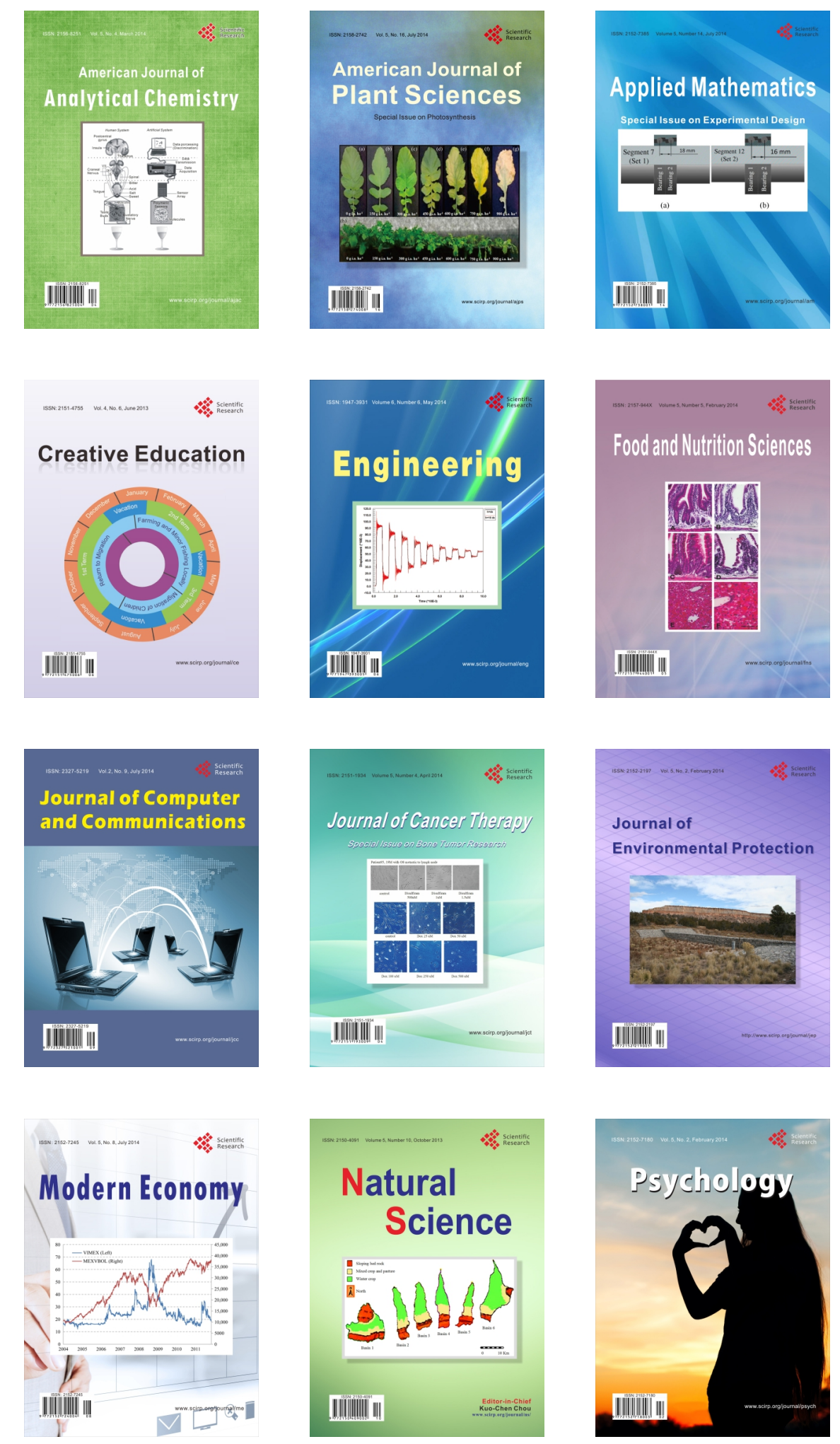